\title{
Risk assessment of corroded casing based on analytic hierarchy process and fuzzy comprehensive evaluation
}

\author{
Sheng-Shan Chen ${ }^{1} \cdot$ Han-Xiang Wang ${ }^{1} \cdot$ Hao Jiang ${ }^{1} \cdot$ Ya-Nan Liu ${ }^{1} \cdot$ Yan-Xin Liu ${ }^{1}$ Xiao-Xiao Lv ${ }^{1}$
}

Received: 18 March 2020 / Published online: 16 September 2020

(c) The Author(s) 2020

\begin{abstract}
Casing corrosion during $\mathrm{CO}_{2}$ injection or storage results in significant economic loss and increased production risks. Therefore, in this paper, a corroded casing risk assessment model based on analytic hierarchy process and fuzzy comprehensive evaluation is established to identify potential risks in time. First, the corrosion rate and residual strength characteristics are analyzed through corrosion tests and numerical simulations, respectively, to determine the risk factors that may lead to an accident. Then, an index system for corroded casing risk evaluation is established based on six important factors: temperature, $\mathrm{CO}_{2}$ partial pressure, flow velocity, corrosion radius, corrosion depth and wellhead pressure. Subsequently, the index weights are calculated via the analytic hierarchy process. Finally, the risk level of corroded casing is obtained via the fuzzy comprehensive evaluation. The corroded casing risk assessment model has been verified by a case well, which shows that the model is valuable and feasible. It provides an effective decision-making method for the risk evaluation of corroded casing in $\mathrm{CO}_{2}$ injection well, which is conductive to improve the wellbore operation efficiency.
\end{abstract}

Keywords Corrosion rate $\cdot$ Residual strength $\cdot$ Analytic hierarchy process $\cdot$ Fuzzy comprehensive evaluation

\section{Introduction}

Injecting $\mathrm{CO}_{2}$ into the depleted oil reservoirs for storage or to enhance oil and gas production is considered as one of the effective measures to reduce the content of $\mathrm{CO}_{2}$ in the atmosphere (Ajayi et al. 2019; Kalra et al. 2018; Khather et al. 2019). However, as an acid gas, $\mathrm{CO}_{2}$ is highly corrosive in water-containing environment (Zhu and Liu 2018). After operating under highly corrosive conditions for a certain period, the casing of $\mathrm{CO}_{2}$ injection wells in Shengli Oilfield exhibited serious corrosion behavior, posing a threat to well safety and severely limiting the promotion of $\mathrm{CO}_{2}$-enhanced oil recovery technology. In addition, some $\mathrm{CO}_{2}$ injection wells are modified from legacy oil wells that have been in service for a long time (Laumb et al. 2016), so casing corrosion problems are inevitable. Laumb et al. (2016) presented

\section{Edited by Xiu-Qiu Peng}

\section{Han-Xiang Wang}

wanghx_upc@163.com

1 College of Mechanical and Electronic Engineering, China University of Petroleum (East China), Qingdao 266580, China two cases of Weyburn Oilfield and proposed that the casing corrosion ranges from small pits to complete penetration in a $\mathrm{CO}_{2}$-rich environment. In one of the case wells, the entire lower section of casing was completely corroded during the 6-year time period when $\mathrm{CO}_{2}$ was injected. Therefore, it is important to study the corroded casing risk assessment of the $\mathrm{CO}_{2}$ injection wells to ensure the safe operation of these wells.

In academia, scholars have performed many studies on $\mathrm{CO}_{2}$ corrosion behaviors of casing and pipeline steel. Sun et al. (2020) explored the phase behavior of impure $\mathrm{CO}_{2}$ streams and proposed that $\mathrm{H}_{2} \mathrm{~S}$-induced phase distribution changes in $\mathrm{CO}_{2}$ streams were responsible for the increased corrosion of X65 steel. Sui et al. (2018) investigated the corrosion behavior of X65 carbon steel in water-saturated supercritical $\mathrm{CO}_{2}$ containing $\mathrm{H}_{2} \mathrm{~S}$ and proposed that the highest corrosion rate was $0.19 \mathrm{~mm} /$ year at $35^{\circ} \mathrm{C}$ and $8 \mathrm{MPa}$. Lin et al. (2016) established two theoretical models for casing strength degradation due to corrosion and proposed that stress concentration factor increased exponentially, while residual burst strength and collapse strength decreased linearly with the increase in corrosion depth. Elgaddafi et al. (2016) investigated the effects of $\mathrm{CO}_{2}$ partial pressure ratio and total pressure on corrosion behavior of $\mathrm{C} 110$ carbon 
steel and proposed that $\mathrm{CO}_{2}$ partial pressure ratio and total pressure determined the type of protective scale, which affected the corrosion process considerably. Li et al. (2017) studied the corrosion behavior of N80 carbon steel under the coexistence of stress and crevice in the $\mathrm{CO}_{2}$-saturated $\mathrm{NaCl}$ solution containing acetic acid and proposed that there was a synergistic effect of stress and crevice on the corrosion of steel.

These previous studies have analyzed the corrosion mechanism of steel and the mechanical properties after corrosion, which fully demonstrated that corrosion will seriously reduce the performance of casing and even lead to a high risk of casing leakage. However, there is a lack of risk assessment model to evaluate the corroded casing risk in the $\mathrm{CO}_{2}$ injection well. Evaluating the risk of corroded casing and adopting different construction process parameters according to the risk level can effectively improve production efficiency and reduce economic losses (Wang et al. 2018; Duguid et al. 2019; Guo et al. 2016a, b). Zeng et al. (2017) established a sustained casing pressure risk assessment model with fuzzy comprehensive evaluation method and provided a clear risk identification and hierarchical management method utilizing limited resources. Wang and Duan (2019) established a comprehensive and objective risk assessment model of oil and gas pipelines based on an improved analytic hierarchy process and technique for order preference by similarity to an ideal solution to identify potential hazards in time. Hence, in this paper, a corroded casing risk assessment model based on analytic hierarchy process and fuzzy comprehensive evaluation is established.

First, the corrosion tests of casing steel are realized by simulating the dynamic $\mathrm{CO}_{2}$ fluid environment with autoclave. The formed corrosion morphology is characterized by scanning electron microscope (SEM) and 3D digital microscope. Next, based on the geometric characteristics of pitting corrosion from the corrosion results, the residual strength characteristics of corroded casing are determined by ANSYS simulation. Then, the index weight is computed by the analytic hierarchy process based on the characteristics of corrosion rate and residual strength. Finally, the risk assessment of corroded casing under different working conditions is realized by establishing a fuzzy comprehensive evaluation model.

\section{Basic principle and theory}

\subsection{Calculation method of average corrosion rate}

Currently, the most typical calculation of the average corrosion rate is expressed by mass loss (William Carey et al. 2010, Li et al. 2020). According to the international standard of NACE RP0775-2005 (Sim et al. 2013) which is widely used in the oil and service industry, the calculation formula for the annual metal corrosion rate is as follows:

$C_{r}=\frac{3.65 \times 10^{5} \times \Delta W}{A \times \rho \times t}$

where $C_{r}$ represents the average corrosion rate $(\mathrm{mm} / \mathrm{a}) ; \Delta W$ represents the loss mass of specimen after corrosion (g); $A$ represents the area of the specimen $\left(\mathrm{mm}^{2}\right) ; \rho$ represents the density of specimen $\left(\mathrm{g} / \mathrm{cm}^{3}\right)$; and $t$ represents the experimental time, days (d).

\subsection{Evaluation criterion of residual strength}

The fourth strength theory is the most commonly used method for evaluating mechanical strength (Liu 2009), and its theoretical formula is expressed by Eq. (2):

$\sigma_{s}=\sqrt{\frac{1}{2}\left[\left(\sigma_{1}-\sigma_{2}\right)^{2}+\left(\sigma_{2}-\sigma_{3}\right)^{2}+\left(\sigma_{3}-\sigma_{1}\right)^{2}\right]}$

where $\sigma_{s}$ represents the von Mises equivalent stress; $\sigma_{1}$, $\sigma_{2}, \sigma_{3}$ represent the principal stresses in three directions, respectively.

According to the fourth strength theory, if the maximum von Mises equivalent stress of the casing exceeds the yield strength of casing steel, the casing will undergo permanent plastic deformation. The load that makes the casing stress reach yield strength is the ultimate load of casing within the safe working range. In this paper, the difference value between the yield strength and von Mises equivalent stress under working pressure is adopted as a criterion to evaluate the residual strength of the corroded casing.

\subsection{Risk assessment methods}

Fuzzy comprehensive evaluation is a comprehensive evaluation method based on fuzzy mathematics (Zeng et al. 2017; Zhang et al. 2009). It makes quantitative judgments on the comprehensiveness of the main characteristics of the external behavior of the system affected by various interfering factors through fewer statistical data (Song et al. 2015; Wang et al. 2012). It is suitable for solving fuzzy and difficult to quantify problems, especially various non-deterministic problems.

The risk assessment of corroded casing is affected by various complicated and changeable environmental factors. There are few statistical data, and it is difficult to obtain statistical characteristics. Therefore, it is suitable to apply fuzzy comprehensive evaluation method for risk assessment of corroded casing. The fuzzy comprehensive evaluation method mainly includes two parts: evaluation index value and evaluation index weight. In this paper, the evaluation index value is determined by the membership function, 
while the evaluation index weight is determined by the analytic hierarchy process.

The analytic hierarchy process is a structured technique for organizing and analyzing complex decisions, based on mathematics and psychology (Guo et al. 2020; Wang and Duan 2019). It decomposes the elements related to decision-making into levels such as goals, criteria and plans and then performs qualitative and quantitative analysis on this basis (Guo et al. 2016a, b; Hu et al. 2018). It has particular application in group decision-making and is used around the world in a wide variety of decision situations, in fields such as government, business, industry, health care, shipbuilding and education. It represents an accurate approach for quantifying the weights of decision criteria. Therefore, in this paper, the analytic hierarchy process is adopted to calculate the evaluation index weights for the corroded casing risk

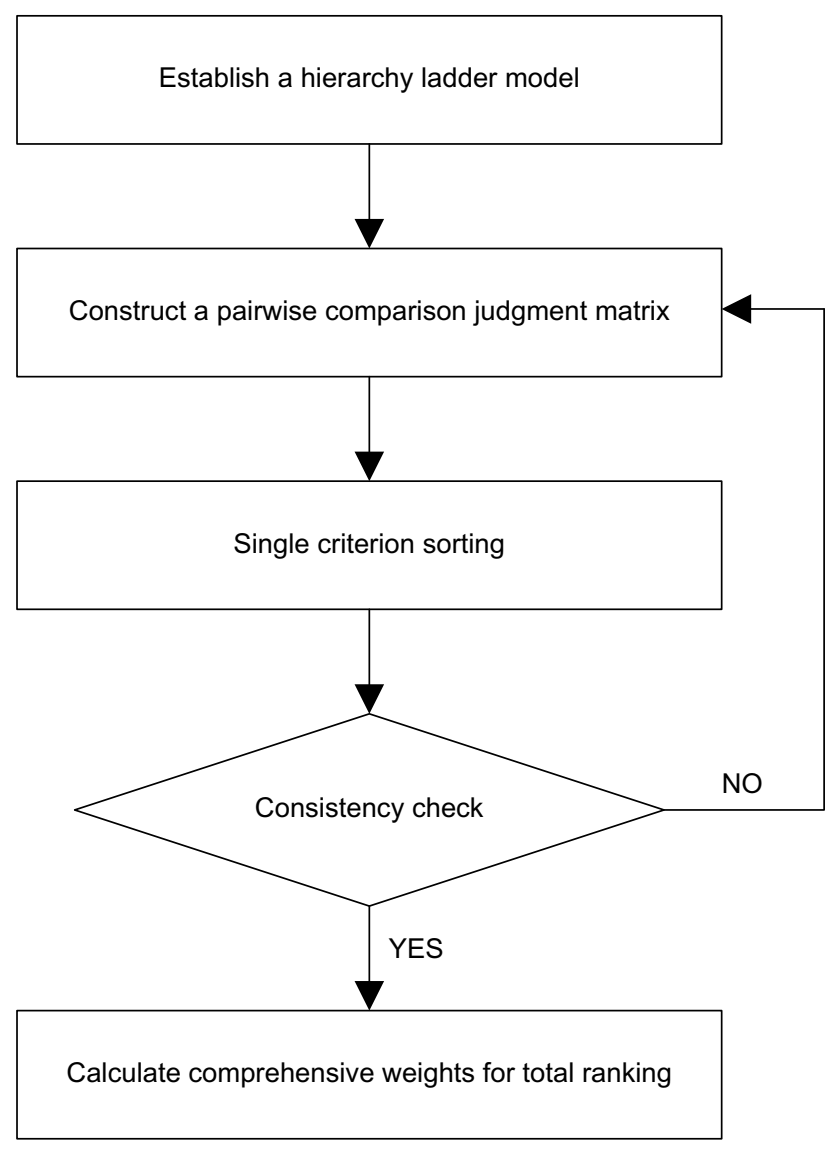

Fig. 1 Basic process of the analytic hierarchy process assessment. The basic steps of the analytic hierarchy process are shown in Fig. 1.

\section{Experiment and simulation}

\subsection{Corrosion test}

The test specimens are processed into a size of $50 \mathrm{~mm} \times 10 \mathrm{~mm} \times 3 \mathrm{~mm}$ from $\mathrm{N} 80$ casing steel. The surface of each specimen is ground to 1000-grit silicon carbide paper, cleaned by absolute ethanol and dried with cold air. Then, the specimens are weighted by an electronic balance with a precision of $0.1 \mathrm{mg}$ and stored in a vacuum desiccator before the tests. Test solution is made up from analytical grade reagents and deionized water simulating the formation water drawn out from Oilfield. The chemical composition is given in Table 1. Before the test, deoxidize the solution with nitrogen for more than $4 \mathrm{~h}$. Then, the corrosion tests of casing specimens are conducted according to the corrosion conditions (Table 2).

\subsection{Numerical simulation}

There are various types of corrosion, some are very common and can be seen in day-to-day life, while the others are rarely seen except in very specific combinations of material and environments. As one of the most common corrosion forms on casing, pitting corrosion seriously affects the strength and service life of casing (Cerit 2019; Mohammed et al. 2019). Therefore, based on the corrosion test results and previous works (Guo et al. 2015; Li et al. 2017; Sun et al. 2017), in this paper, the corroded casing model is established with a shallow spherical shape.

It is difficult to establish the same experimental conditions on land as the harsh downhole environment. Fortunately, the finite element method software ANSYS can provide detailed information on the structural mechanics (Marques et al. 2018). In addition, previous work (Yan et al.

Table 2 Corrosion conditions for test

\begin{tabular}{llll}
\hline Temperature, ${ }^{\circ} \mathrm{C}$ & 40 & 60 & 80 \\
\hline $\mathrm{CO}_{2}$ partial pressure, $\mathrm{MPa}$ & 1.5 & 2.5 & 3.5 \\
Flow velocity, $\mathrm{m} / \mathrm{s}$ & 0.3 & 0.6 & 0.9 \\
Experimental time, days & 7 & & \\
\hline
\end{tabular}

Table 1 Chemical composition of test solution

\begin{tabular}{llllllll}
\hline Composition & $\mathrm{K}^{+}, \mathrm{Na}^{+}$ & $\mathrm{Mg}^{2+}$ & $\mathrm{Ca}^{2+}$ & $\mathrm{Cl}^{-}$ & $\mathrm{SO}^{2-}$ & $\mathrm{HCO}^{-}$ & Total ion concentration \\
\hline Concentration, $\mathrm{mg} / \mathrm{L}$ & 7775 & 12 & 722 & 10,838 & 338 & 363 & 20,048 \\
\hline
\end{tabular}


2019) also proves that the calculation of corroded casing with ANSYS is consistent with the actual situation. Therefore, a stratum-cement ring-casing simulation model is established based on the wellbore structure to investigate the effects of the corrosion radius, corrosion depth and wellhead pressure on the corroded casing (Fig. 2). The load includes wellhead pressure and formation pressure. The model simulates the working condition at the bottom of a 2000-m-deep well. Based on the geological situation of Shengli Oilfield, the maximum horizontal formation pressure is set to $45.42 \mathrm{MPa}$, the minimum horizontal formation pressure is $32.35 \mathrm{MPa}$, and the vertical formation pressure is $44 \mathrm{MPa}$. To simplify the calculation reasonably, the operation pressure in casing equals wellhead pressure plus hydrostatic pressure (20 MPa). The steel grade of casing is N80, whose yield strength is $552 \mathrm{MPa}$, diameter is $177.8 \mathrm{~mm}$, thickness is $10.36 \mathrm{~mm}$, Young's modulus is $206 \mathrm{GPa}$, Poisson ratio is 0.3 , and density is $7800 \mathrm{~kg} / \mathrm{m}^{3}$ (Mohammed et al. 2019; Wen et al. 2010; Han et al. 2014). The calculation conditions of pitting corrosion are given in Table 3 .

\section{Results and discussion}

\subsection{Discussion of corrosion test results}

The corrosion rates are measured to determine the corrosion behavior of $\mathrm{N} 80$ steel in liquid $\mathrm{CO}_{2}$ mixtures. The corrosion specimens are exposed to $\mathrm{CO}_{2}$ mixtures with different conditions as the set scheme. Figure 3 shows the typical SEM surface morphology of N80 steel after the corrosion tests. It can be seen from the SEM images that
Table 3 Calculation conditions of pitting corrosion

\begin{tabular}{llll}
\hline Case & Corrosion radius, mm & $\begin{array}{l}\text { Corrosion } \\
\text { depth, } \mathrm{mm}\end{array}$ & $\begin{array}{l}\text { Wellhead pres- } \\
\text { sure, MPa }\end{array}$ \\
\hline 1 & $4 / 6 / 8 / 10 / 12 / 14 / 16 / 18 / 20$ & 1 & 25 \\
2 & $4 / 6 / 8 / 10 / 12 / 14 / 16 / 18 / 20$ & 2 & 25 \\
3 & $4 / 6 / 8 / 10 / 12 / 14 / 16 / 18 / 20$ & 3 & 25 \\
4 & 8 & $1 / 2 / 3 / 4 / 5 / 6 / 7 / 8$ & 10 \\
5 & 8 & $1 / 2 / 3 / 4 / 5 / 6 / 7 / 8$ & 15 \\
6 & 8 & $1 / 2 / 3 / 4 / 5 / 6 / 7 / 8$ & 20 \\
7 & 8 & 1 & $5 / 10 / 15 / 20 / 25 / 30$ \\
8 & 8 & 2 & $5 / 10 / 15 / 20 / 25 / 30$ \\
9 & 8 & 3 & $5 / 10 / 15 / 20 / 25 / 30$ \\
\hline
\end{tabular}

the corrosion specimens present some corrosion product patches, the closely attached small particles and the local pitting phenomena on the corroded steel surfaces. As shown in Fig. 3a, the corrosion product film is partly detached from the substrate, presenting a local damage of the corrosion layers. As shown in Fig. 3b, there is obvious pitting corrosion on the specimen surface. Additionally, a $3 \mathrm{D}$ digital microscope is used to inspect the corroded specimens to measure the depth of pitting corrosion. Figure 4 shows the typical pitting corrosion profile measurement images. It can be seen from the images that the depth and width of pitting corrosion can be measured clearly using the $3 \mathrm{D}$ profile measurement. The results show that the maximum depth of typical pitting corrosion is $355 \mu \mathrm{m}$ and the maximum width is $2000 \mu \mathrm{m}$. These measurement results provide a data basis for the establishment of the corroded casing simulation model.
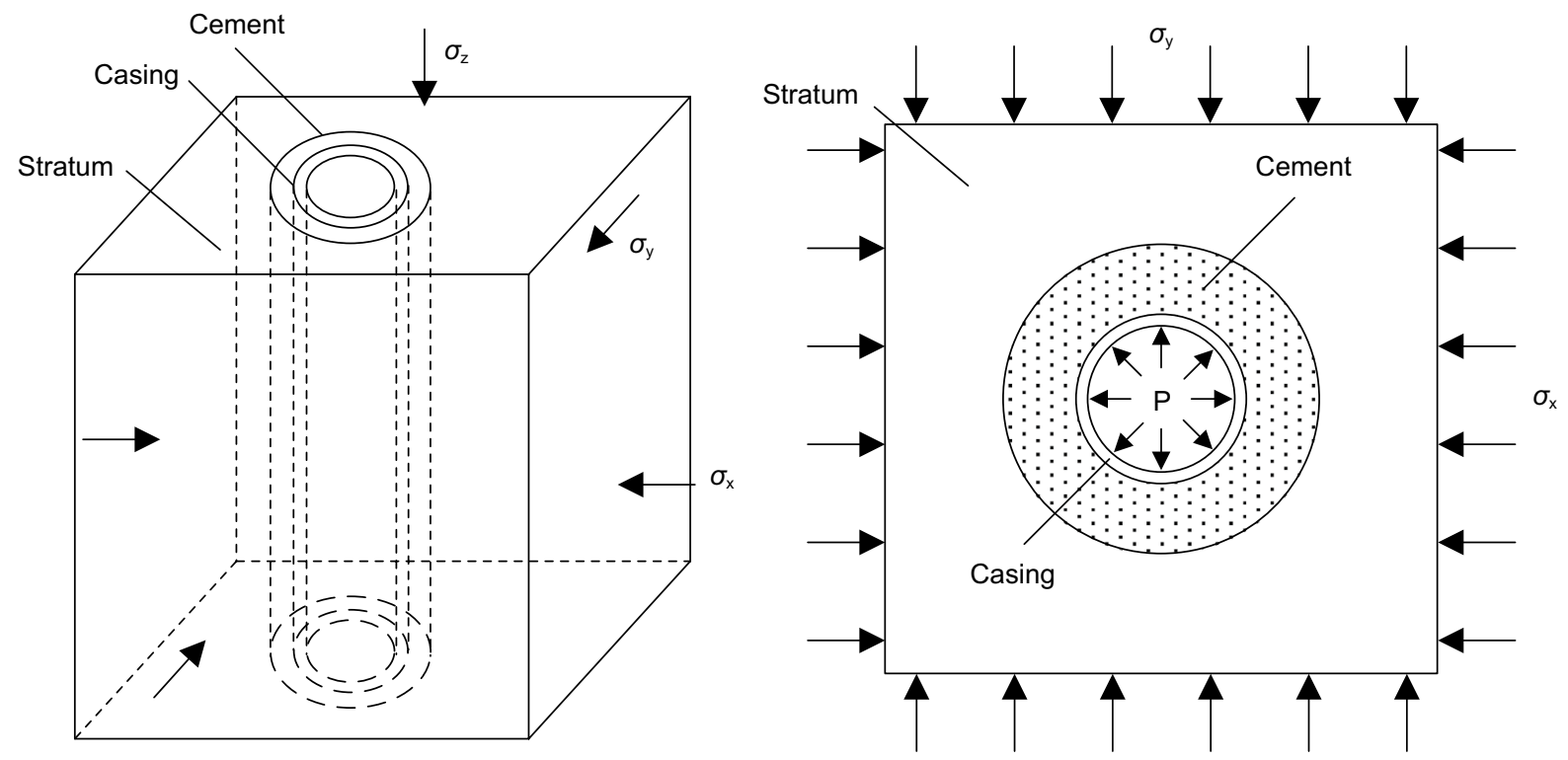

Fig. 2 Casing-cement-formation system simulation model 

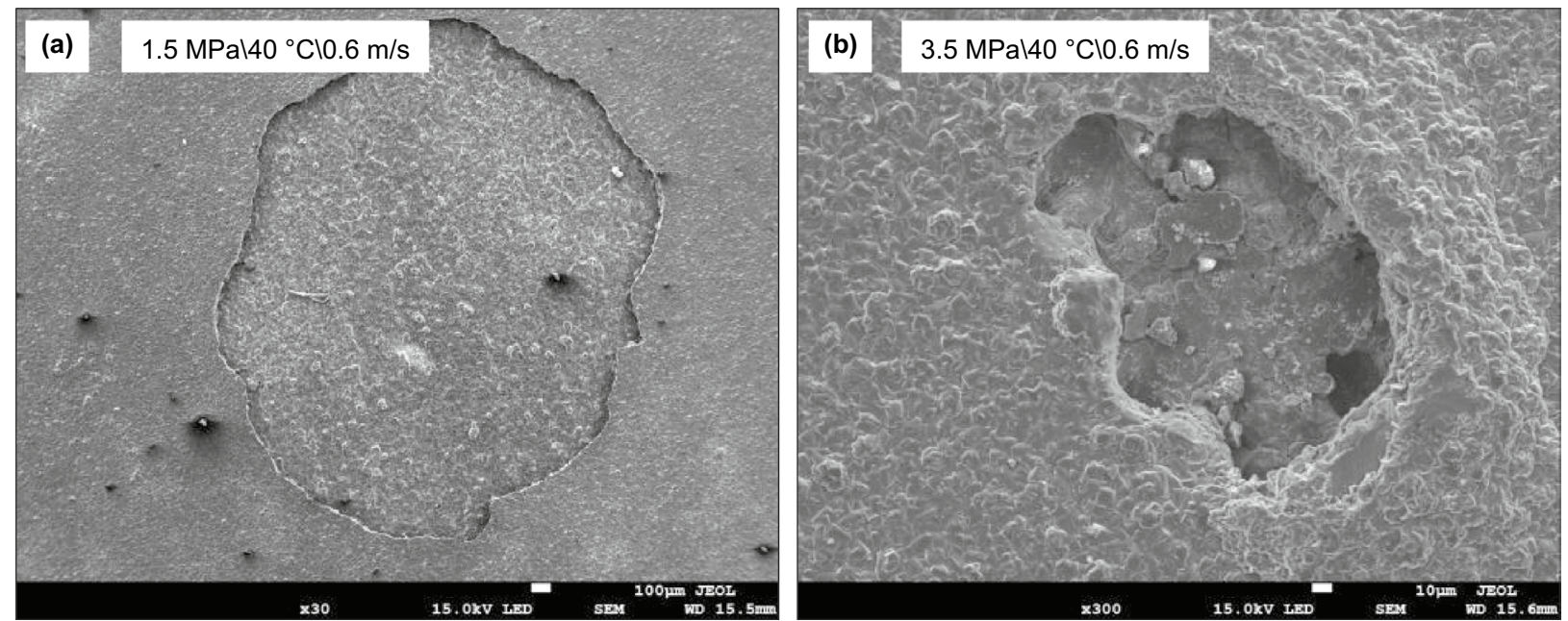

Fig. 3 Typical SEM surface morphology of corroded specimens after corrosion tests
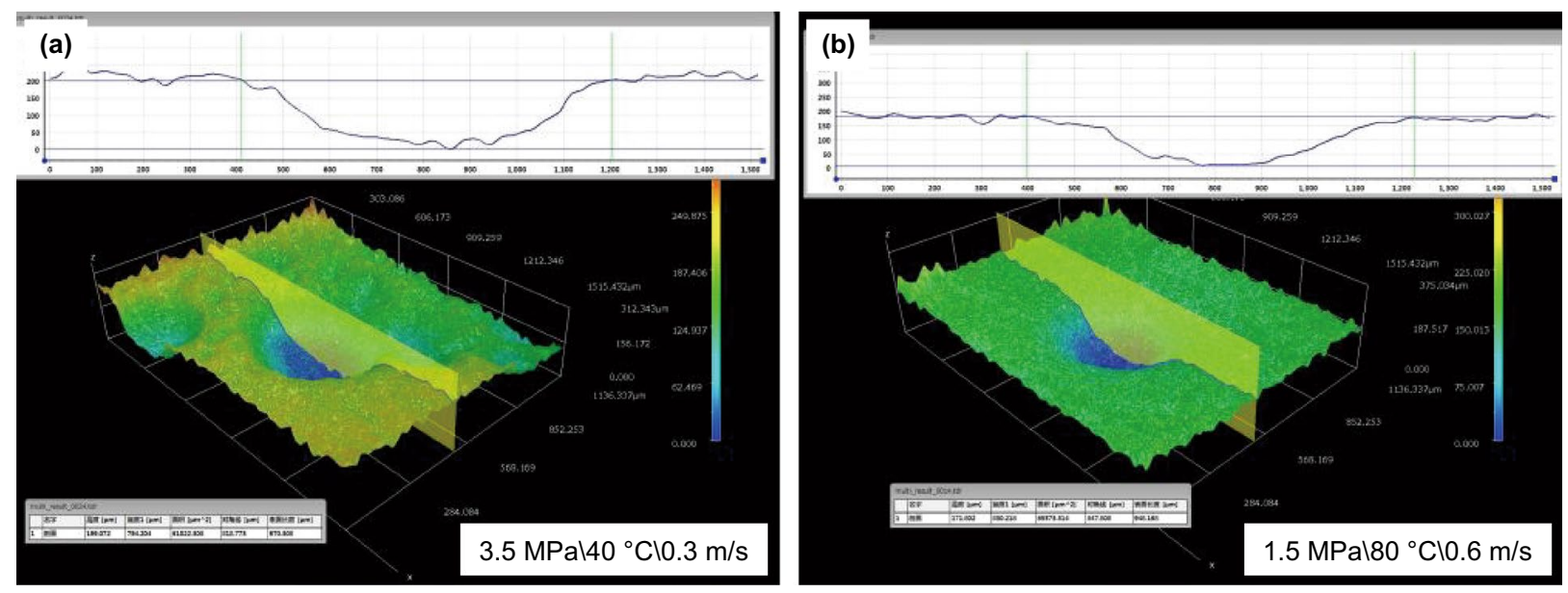

Fig. 4 Typical pitting corrosion depth and width measurement images

\subsubsection{Effect of temperature}

Figure 5 shows the averaged corrosion rates of N80 steel at different temperatures. Temperature has a significant effect on the corrosion rate. As the test temperature increases, the specimen corrosion rate increases approximately linearly within the range of experimental parameters. On average, the corrosion rate increases by approximately $1 \mathrm{~mm} / \mathrm{a}$ for each $20^{\circ} \mathrm{C}$ increase in test temperature. By analyzing the corrosion mechanism, the influence of temperature on the corrosion rate is the result of a combination of factors (Sun et al. 2012; Okoro et al. 2019; Rizzo et al. 2020). On the one hand, temperature affects the speed of ion activity. Ionic activity accelerates with increasing temperature, which accelerates chemical and electrochemical reactions and ultimately

increases the corrosion rate. Conversely, the solubility of $\mathrm{CO}_{2}$ in corrosive medium decreases with increasing temperature, thereby reducing the corrosion rate. In addition, temperature also affects the formation of corrosion products. When the temperature is higher than a certain value, dense corrosion products are formed on the surface of specimen, which separates specimen from the corrosive medium (Hua et al. 2019), thereby protecting the specimen and reducing the corrosion rate. Corrosion test results show that the total corrosion rate of casing steel increases with increasing temperature. This indicates that in the current corrosive environment, the increasing corrosion rate affected by ionic activity is greater than the decreasing corrosion rate affected by solubility and corrosion product. 


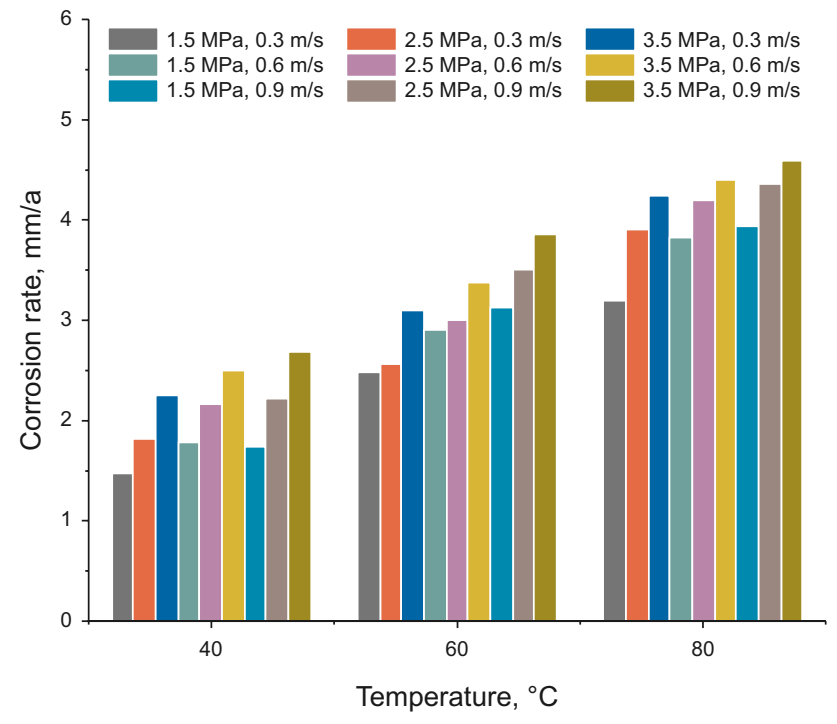

Fig. 5 Effect of temperature on corrosion rate

\subsubsection{Effect of $\mathrm{CO}_{2}$ partial pressure}

Figure 6 shows the averaged corrosion rates of N80 steel under different $\mathrm{CO}_{2}$ partial pressures. It can be seen that the corrosion rate increases with the increase in $\mathrm{CO}_{2}$ partial pressure within the range of experimental parameters. On average, the corrosion rate increases by approximately $0.2 \mathrm{~mm} / \mathrm{a}$ for each $1 \mathrm{MPa}$ increase in $\mathrm{CO}_{2}$ partial pressure. The main reason for this characteristic is that the $\mathrm{CO}_{2}$ partial pressure affects the $\mathrm{pH}$ of the solution medium. The increase in $\mathrm{CO}_{2}$ partial pressure makes solution $\mathrm{pH}$ decrease and depolarization of hydrogen ions increase. Previous studies (Fu et al. 2016; Chen et al. 2018) have shown that the lower the $\mathrm{pH}$ of the acidic solution, the more severe the $\mathrm{CO}_{2}$ corrosion.

\subsubsection{Effect of flow velocity}

Figure 7 shows the averaged corrosion rates of N80 steel at different flow velocity. It can be seen that the corrosion rate increases with the increase in flow velocity within the range of experimental parameters. This is because the higher flow velocity makes it easier to rinse off the solution and loose corrosion products on the specimen surface, thereby inhibiting the generation of corrosion product films. Moreover, high flow velocity can accelerate the mass transfer process and enhance the transportation of reactive species $\left(\mathrm{H}^{+}\right.$, $\mathrm{HCO}_{3}{ }^{-}, \mathrm{H}_{2} \mathrm{CO}_{3}$ ) toward the electrode surface, accelerating the cathodic reaction (Zhang et al. 2013; Zhong et al. 2020). On average, the effect of flow velocity on the corrosion rate is slightly smaller than the effect of partial pressure.

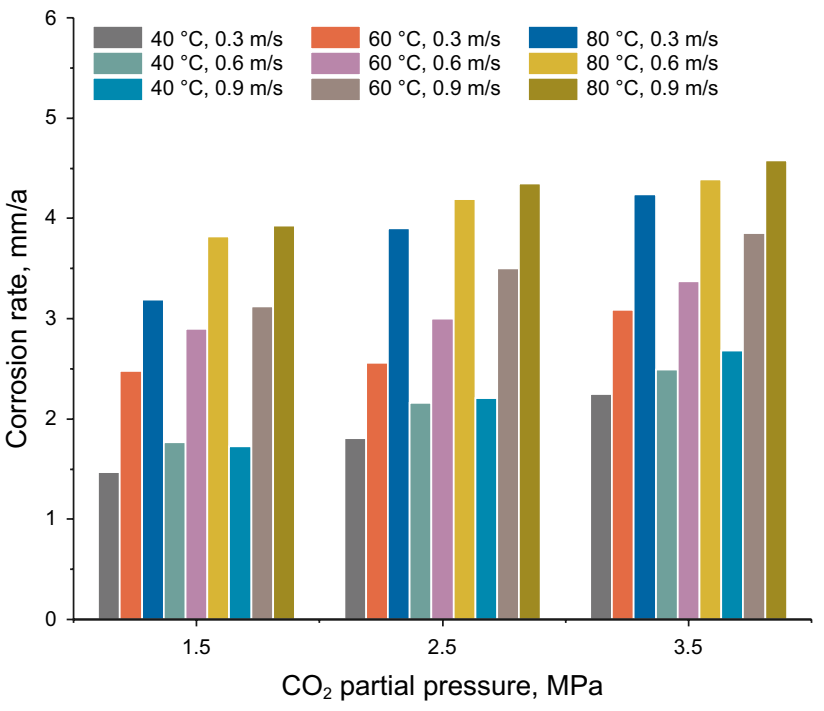

Fig. 6 Effect of $\mathrm{CO}_{2}$ partial pressure on corrosion rate

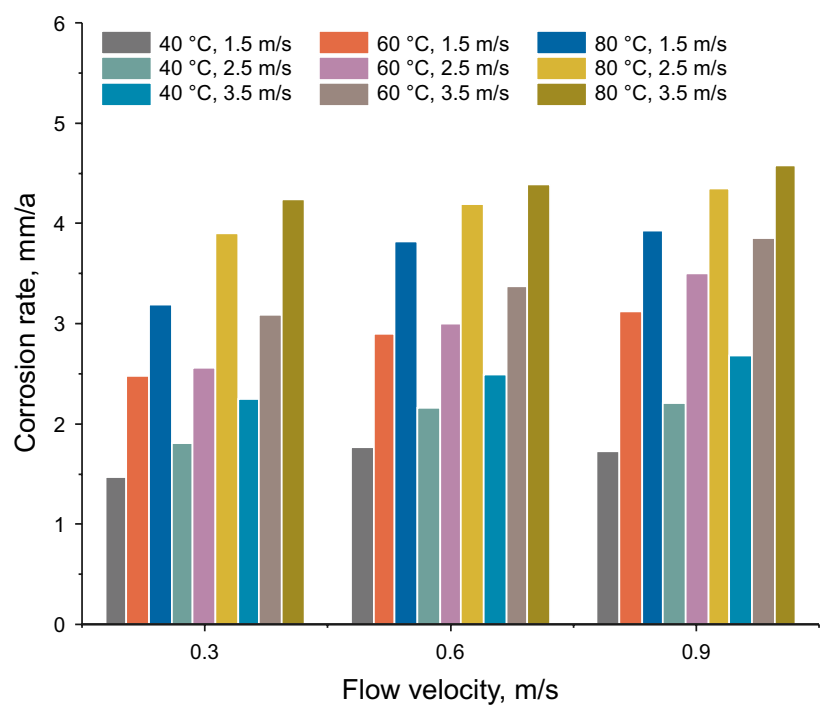

Fig. 7 Effect of flow velocity on corrosion rate

\subsection{Discussion of residual strength simulation results}

\subsubsection{Effect of corrosion radius}

Figure 8 shows the residual strength of casing with different pitting corrosion radii under $15 \mathrm{MPa}$ wellhead pressure. It can be seen that the residual strength of corroded casing increases slightly with the increase in pitting corrosion radius. Taking the casing with a corrosion depth of $1 \mathrm{~mm}$, $2 \mathrm{~mm}$ and $3 \mathrm{~mm}$ as the analysis object, when the pitting corrosion radius increases from $4 \mathrm{~mm}$ to $20 \mathrm{~mm}$, the maximum 


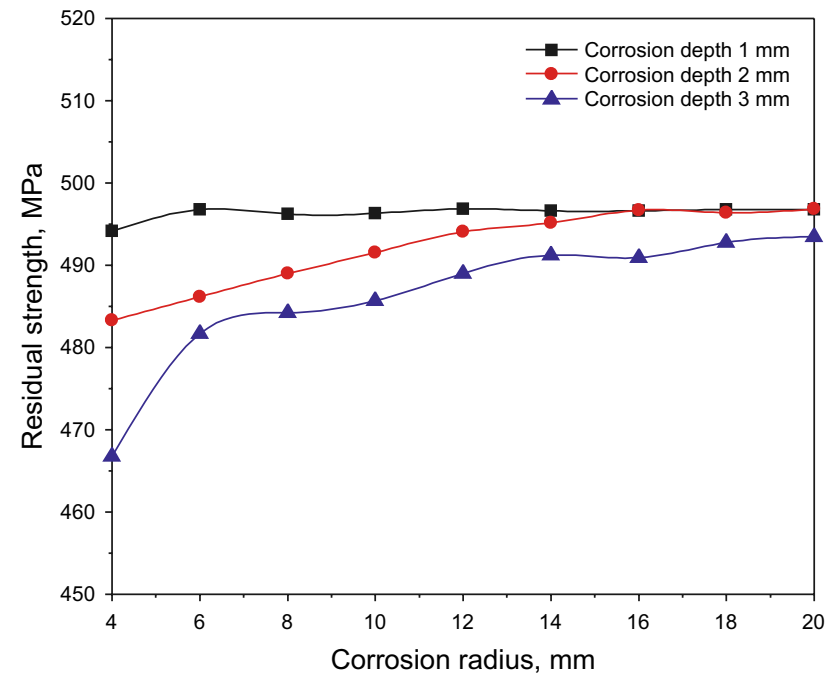

Fig. 8 Effect of corrosion radius on residual strength of casing

increment of residual strength is approximately $25 \mathrm{MPa}$. When the corrosion radius is small, the difference in residual strength between different corrosion depths is obvious. With the increase in corrosion radius, the difference in residual strength between different corrosion depths decreases gradually. When the corrosion radius is greater than $14 \mathrm{~mm}$, the casing residual strength hardly varies with the increase in the radius.

\subsubsection{Effect of corrosion depth}

Figure 9 shows the residual strength of casing with different pitting corrosion depths at a corrosion radius of $8 \mathrm{~mm}$. It can be seen that the residual strength of corroded casing decreases substantially linearly with the increase in pitting corrosion depth. This is because the increase in corrosion depth means the reduction in casing wall thickness, while the maximum working strength of casing is directly proportional to its wall thickness. Therefore, the corrosion of casing causes a reduction in the wall thickness, resulting in a reduction in its residual strength.

\subsubsection{Effect of wellhead pressure}

Figure 10 shows the residual strength of casing with different wellhead pressures at a corrosion radius of $8 \mathrm{~mm}$. It can be seen that the residual strength of corroded casing increases first and then decreases with the wellhead pressure increases. When the wellhead pressure is lower than $10 \mathrm{MPa}$, the residual strength of corroded casing shows a slight increase trend with the increase in pressure. When the wellhead pressure is greater than $10 \mathrm{MPa}$, the residual strength of corroded casing decreases linearly with the increase in pressure. When the wellhead pressure increases by $5 \mathrm{MPa}$, the residual strength

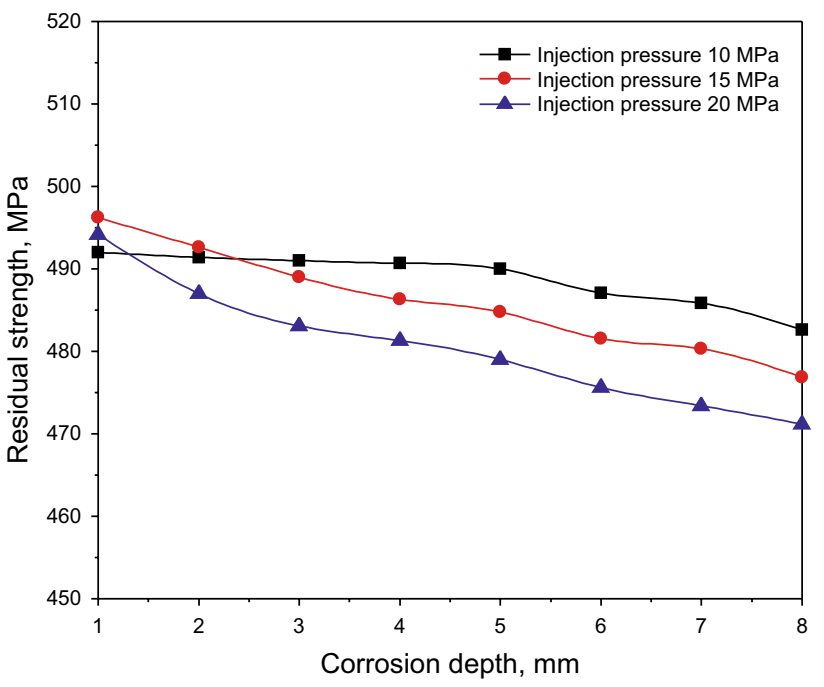

Fig. 9 Effect of corrosion depth on residual strength of casing

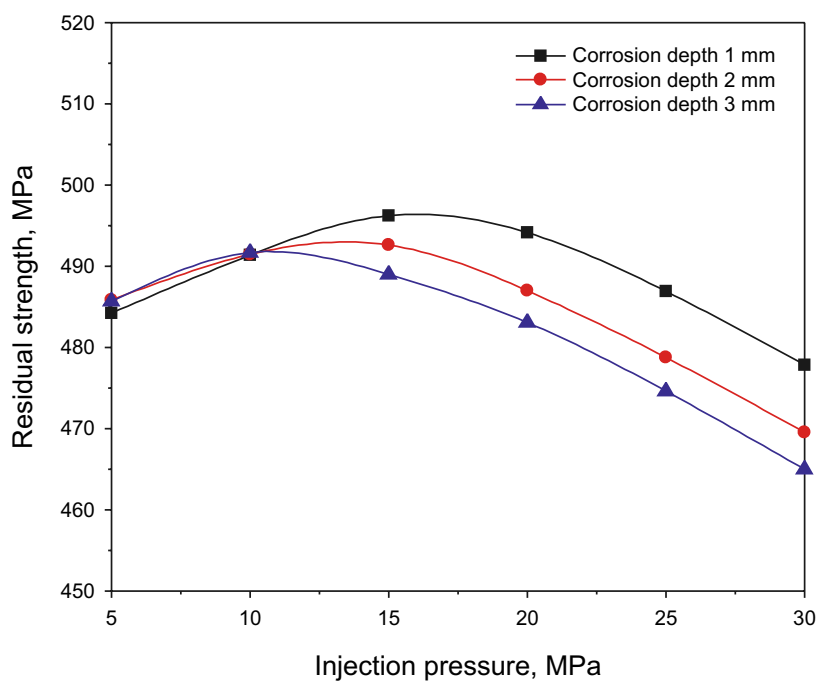

Fig. 10 Effect of wellhead pressure on residual strength of casing

decreases by approximately $10 \mathrm{MPa}$. This finding can be explained as follows:

In the absence of wellhead pressure, at a depth of 2000 meters, there are $20 \mathrm{MPa}$ hydrostatic pressures inside the casing and 32.35-45.42 MPa formation pressures outside the casing. With the wellhead pressure increases from $0 \mathrm{MPa}$, the pressure inside the casing increases accordingly, which reduces the pressure difference between the inside and outside of the casing. Therefore, when the internal pressure is less than the external pressure, the residual strength of casing increases with the increase in wellhead pressure. When the internal pressure is equal to the external formation pressure, the maximum residual strength of the casing is reached. When the internal pressure exceeds the external formation pressure, 


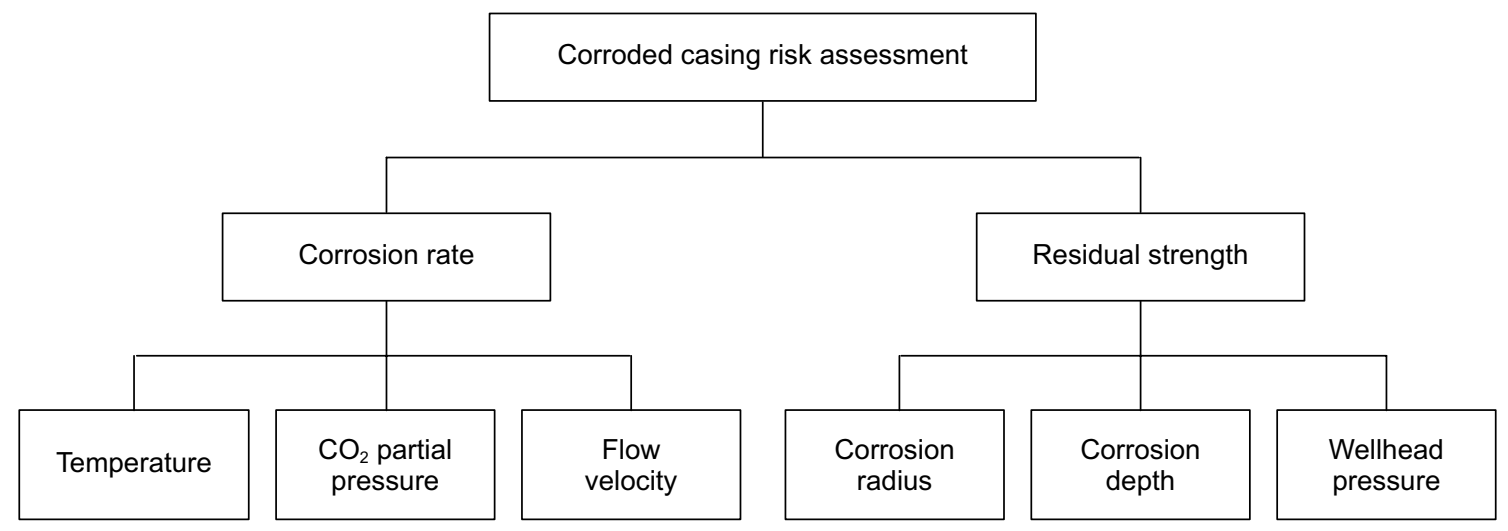

Fig. 11 Hierarchical model of casing corrosion risk

the pressure difference between the inside and outside of the casing increases with the increase in wellhead pressure, resulting in the decrease in the residual strength of the casing.

\subsection{Corrosion risk assessment}

\subsubsection{Determination of evaluation index weight}

Based on the principles of scientificity, rationality and representativeness, in this paper, two first-tiered indices and six second-tiered indices are put forward through the analytic hierarchy process. The evaluation index system of corroded casing failure risk in the $\mathrm{CO}_{2}$ injection well is shown in Fig. 11.

The first-tiered indices include corrosion rate (U1) and residual strength (U2), while the second-tiered indices include temperature (V1), $\mathrm{CO}_{2}$ partial pressure (V2), flow velocity (V3), corrosion depth (V4), corrosion radius (V5) and wellhead pressure (V6). Then, judgment matrices are constituted by pairwise comparison according to Saaty 1-9 scales shown in Table 4 (Guo et al. 2020; Gao et al. 2010). On the basis of experts' experience, corrosion tests and numerical simulation results, the judgment matrices of first-tiered index (A) and second-tiered index (B1, B2) are shown in Tables 5, 6 and 7.

The weight of each index is obtained by solving the eigenvectors of the judgment matrix (Saaty 1998). The results of first-tiered index weights, second-tiered index weights and the total relative weights are shown in Table 8 .

Once the eigenvectors are calculated, a consistency test should be made to calculate the consistency ratio coefficient (Hu et al. 2018; Wang et al. 2012):

$\mathrm{CI}=\frac{\lambda-n}{n-1}$
Table 4 Analytic hierarchy process judgment matrix 1-9 scales and their implications

\begin{tabular}{ll}
\hline Scale & Implication \\
\hline 1 & Two factors with the same importance \\
3 & One factor slightly more important than the other \\
5 & One factor obviously more important than the other \\
7 & One factor greatly more important than the other \\
9 & One factor extremely more important than the other \\
$2,4,6,8$ & The medium value of the two adjacent scales above \\
Factors $i$ and $j$ determine the value of $C_{i j}$, so the factors $j$ and $i$ \\
determine the reciprocal value $C_{j i}=1 / C_{i j}$
\end{tabular}

Table 5 Judgment matrix of first-tiered index

\begin{tabular}{lll}
\hline First-tiered index (A) & U1 & U2 \\
\hline U1 & 1 & 1 \\
U2 & 1 & 1 \\
\hline
\end{tabular}

Table 6 Judgment matrix of second-tiered index of corrosion rate

\begin{tabular}{llll}
\hline Second-tiered index (B1) & V1 & V2 & V3 \\
\hline V1 & 1 & 4 & 5 \\
V2 & $1 / 4$ & 1 & 2 \\
V3 & $1 / 5$ & $1 / 2$ & 1 \\
\hline
\end{tabular}

Table 7 Judgment matrix of second-tiered index of residual strength

\begin{tabular}{llll}
\hline Second-tiered index (B2) & V4 & V5 & V6 \\
\hline V4 & 1 & 7 & 3 \\
V5 & $1 / 7$ & 1 & $1 / 5$ \\
V6 & $1 / 3$ & 5 & 1 \\
\hline
\end{tabular}


Table 8 Weight of each index

\begin{tabular}{lllll}
\hline First-tiered index & First-tiered weight & Second-tiered index & Second-tiered weight & Relative weights \\
\hline Corrosion rate & 0.5 & Temperature (V1) & 0.681 & 0.340 \\
& & $\mathrm{CO}_{2}$ partial pressure (V2) & 0.201 & 0.101 \\
Residual strength & \multirow{2}{*}{0.5} & Flow velocity (V3) & 0.118 & 0.059 \\
& & Corrosion depth (V4) & 0.643 & 0.322 \\
& & Corrosion radius (V5) & 0.074 & 0.037 \\
& Wellhead pressure (V6) & 0.283 & 0.141 \\
\hline
\end{tabular}

Table 9 Values of $R I$

\begin{tabular}{llllllllll}
\hline$n$ & 1 & 2 & 3 & 4 & 5 & 6 & 7 & 8 & 9 \\
\hline RI & 0 & 0 & 0.58 & 0.94 & 1.12 & 1.24 & 1.32 & 1.41 & 1.45 \\
\hline
\end{tabular}

$\mathrm{CR}=\frac{\mathrm{CI}}{\mathrm{RI}}$

where $\lambda$ is the maximum eigenvalue; $n$ is the order of judgment matrix; and RI is the average random consistency index which can be obtained from Table 9. When $C R<0.1$, the consistency of the judgment matrix is considered as being satisfactory, which means the weight distribution is reasonable. Otherwise, the matrix must be adjusted until the consistency is satisfied.

The judgment matrices $\mathrm{A}, \mathrm{B} 1, \mathrm{~B} 2$ have the maximum eigenvalue $\lambda_{\mathrm{A}}=2, \lambda_{\mathrm{B} 1}=3.025, \lambda_{\mathrm{B} 2}=3.065$, respectively. $\mathrm{CI}_{\mathrm{A}}=0$ means that the matrix $\mathrm{A}$ is completely consistent and meets the requirements. Meanwhile, the consistency ratios can be calculated as follows: $\mathrm{CR}_{B 1}=0.022<0.1$, $\mathrm{CR}_{B 2}=0.056<0.1$. Therefore, the eigenvectors of the judgment matrices calculated above can be used as weight vector by checking the consistency index.

\subsubsection{Risk assessment model}

The fuzzy comprehensive evaluation method is adopted to analyze the measured values of indices to obtain the corrosion risk assessment value of the corroded casing. With consideration of corrosion rate tests, residual strength numerical simulations and expert experiences, the corroded casing risk assessment of $\mathrm{CO}_{2}$ injection well in Shengli Oilfield is set to five levels: very low risk, low risk, medium risk, high risk and very high risk, as shown in Table 10 .

In this paper, the risk assessment value is calculated by the ladder distribution membership function; $v_{i j}$ is the $j$ level boundary value of the $i$ factor.

Level 1 membership function $u_{1}(x)=\left\{\begin{array}{l}1 ; \quad x \leq x_{i 1} \\ \frac{v_{i 2}-x}{v_{i 2}-v_{i 1}} ; \quad v_{i 2} \leq x \leq v_{i 2} \\ 0 ; \quad x \geq x_{i 2}\end{array}\right.$

$j(j=2,3,4)$ level membership function

$u_{j}(x)=\left\{\begin{array}{l}0 ; \quad x \leq v_{i(j-1)} \\ \frac{x-v_{i(j-1)}}{v_{i i}-v_{i(j-1)}} ; \quad v_{i(j-1)} \leq x \leq v_{i j} \\ \frac{v_{i(j+1)}-x}{v_{i(j+1)}-v_{i j}} ; \quad v_{i j} \leq x \leq v_{i(j+1)} \\ 0 ; \quad x \geq v_{i(j+1)}\end{array}\right.$

Level 5 membership function

$u_{5}(x)=\left\{\begin{array}{l}0 ; \quad x \leq v_{i 4} \\ \frac{x-v_{i 4}}{v_{i 5}-v_{i 4}} ; \quad v_{i 4} \leq x \leq v_{i 5} \\ 1 ; \quad x \geq v_{i 5}\end{array}\right.$

The analysis process of the comprehensive risk assessment of the corroded casing includes the following three steps:

(a) The six factors including temperature, $\mathrm{CO}_{2}$ partial pressure, flow velocity, corrosion radius, corrosion depth and wellhead pressure are used as the two-tiered indices, and the index weights are calculated by the analytic hierarchy process.

(b) The corrosion membership function is calculated based on the working condition parameters, and a single-factor evaluation matrix is obtained.

(c) The final evaluation vector of corrosion risk is obtained by combining the index weights and the single-factor evaluation matrix. The maximum vector value is the fuzzy comprehensive evaluation result of casing corrosion risk. 
Table 10 Corrosion risk assessment criteria

\begin{tabular}{llcccc}
\hline Assessment indicators & Little risk & Low risk & Medium risk & High risk & Severe risk \\
\hline Temperature, ${ }^{\circ} \mathrm{C}$ & $0-16$ & $16-32$ & $32-48$ & $48-64$ & $64-80$ \\
$\mathrm{CO}_{2}$ partial pressure, $\mathrm{MPa}$ & $0-0.7$ & $0.7-1.4$ & $1.4-2.1$ & $2.1-2.8$ & $2.8-3.5$ \\
Flow velocity, m/s & $0-0.18$ & $0.18-0.36$ & $0.36-0.54$ & $3-54-0.72$ & $0.72-0.9$ \\
Corrosion depth, mm & $0-1.5$ & $1.5-3$ & $8-12$ & $6-6$ & $12-16$ \\
Corrosion radius, mm & $0-4$ & $4-8$ & $10-15$ & $15-20$ & $16-20$ \\
Wellhead pressure, $\mathrm{MPa}$ & $0-5$ & $5-10$ & & $20-25$ \\
\hline
\end{tabular}

\subsubsection{Engineering application analysis}

To evaluate the risk of corroded casing, some necessary parameters need to be prepared in advance. Based on the aforementioned corroded casing risk evaluation model, it can be known that the six basic parameters necessary for the evaluation are temperature, $\mathrm{CO}_{2}$ partial pressure, flow velocity, corrosion radius, corrosion depth and wellhead pressure. The parameters of case well in Shengli Oilfield are shown in Table 11.

Substituting the given parameters of the case well into the corrosion membership function Eqs. (5), (6) and (7), the single-factor evaluation matrix of the corroded casing risk assessment can be obtained:

$$
R=\left[\begin{array}{ccccc}
0 & 0 & 0 & 0.625 & 0.375 \\
0 & 0 & 0.429 & 0.571 & 0 \\
0 & 0.222 & 0.778 & 0 & 0 \\
0 & 0 & 0.667 & 0.333 & 0 \\
0 & 0.5 & 0.5 & 0 & 0 \\
0 & 0 & 1 & 0 & 0
\end{array}\right]
$$

Combining the index weights and the single-factor judgment matrix, the final weight vector of corroded casing risk is calculated as shown in Fig. 12. It can be seen that under the present conditions, the largest final evaluation vector is medium corrosion risk. Therefore, based on fuzzy comprehensive evaluation criteria, the risk of the corroded casing in this case well is medium corrosion risk. Based on the field experience, it is recommended to carry out the workover operation to ensure the safety of the wellbore. The calculated risk results are basically consistent with the condition of this well, and oilfield experts agree with this calculation results.

\section{Conclusions}

On the basis of analytic hierarchy process and fuzzy comprehensive evaluation method, a risk assessment model is established to achieve the risk assessment of corroded casing in $\mathrm{CO}_{2}$ injection well. The following conclusions can be drawn:
Table 11 Operation parameters of $\mathrm{CO}_{2}$ injection well

\begin{tabular}{llllll}
\hline $\begin{array}{l}\text { Tempera- } \\
\text { ture }\end{array}$ & $\begin{array}{l}\mathrm{CO}_{2} \\
\text { partial } \\
\text { pressure }\end{array}$ & $\begin{array}{l}\text { Flow } \\
\text { velocity }\end{array}$ & $\begin{array}{l}\text { Corrosion } \\
\text { radius }\end{array}$ & $\begin{array}{l}\text { Corrosion } \\
\text { depth }\end{array}$ & $\begin{array}{l}\text { Wellhead } \\
\text { pressure }\end{array}$ \\
\hline $70^{\circ} \mathrm{C}$ & $2.5 \mathrm{MPa}$ & $0.5 \mathrm{~m} / \mathrm{s}$ & $10 \mathrm{~mm}$ & $5 \mathrm{~mm}$ & $15 \mathrm{MPa}$ \\
\hline
\end{tabular}

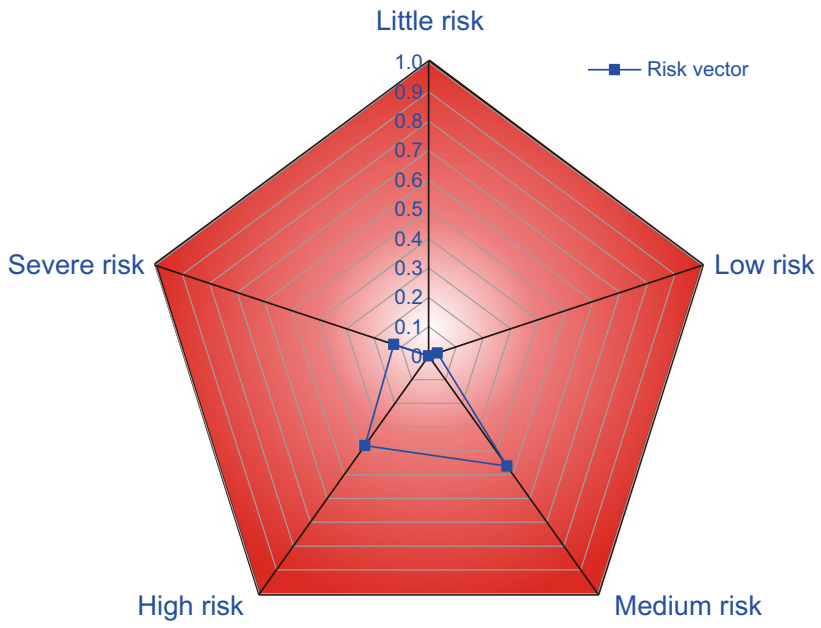

Fig. 12 Results of fuzzy comprehensive evaluation

(a) The corrosion test results show that the corrosion rate of casing steel increases with the increase in temperature, $\mathrm{CO}_{2}$ partial pressure and flow velocity, and there are interactions among various factors. Among them, the effect of temperature is the most serious, followed by $\mathrm{CO}_{2}$ partial pressure.

(b) The numerical simulation results show that the residual strength of corroded casing decreases with the increase in corrosion depth and wellhead pressure, while slightly increases with increasing corrosion radius. Among them, the effect of corrosion depth is the most serious, followed by wellhead pressure.

(c) A corroded casing risk assessment model in $\mathrm{CO}_{2}$ injection well is presented based on analytic hierarchy process and fuzzy comprehensive evaluation. The assessment model is verified by calculation of a case well 
in Shengli Oilfield, which means that it provides an effective decision-making method for multifactor safety evaluation of corroded casing in $\mathrm{CO}_{2}$ injection well.

\begin{abstract}
Acknowledgements This work was supported by the National Natural Science Foundation of China (Grant No. 2016ZX05042004); the Joint Funds of the National Natural Science Foundation of China (Grant no. U1762104); the Major Scientific and Technological Projects of CNPC (Grant No. ZD2019-184-004); the Fundamental Research Funds for the Central Universities (20CX02306A); and the Opening Fund of National Engineering Laboratory of Offshore Geophysical and Exploration Equipment. The authors also would like to express their sincere gratitude to Dr. Zhang Dalei for his assistance in corrosion tests.
\end{abstract}

Open Access This article is licensed under a Creative Commons Attribution 4.0 International License, which permits use, sharing, adaptation, distribution and reproduction in any medium or format, as long as you give appropriate credit to the original author(s) and the source, provide a link to the Creative Commons licence, and indicate if changes were made. The images or other third party material in this article are included in the article's Creative Commons licence, unless indicated otherwise in a credit line to the material. If material is not included in the article's Creative Commons licence and your intended use is not permitted by statutory regulation or exceeds the permitted use, you will need to obtain permission directly from the copyright holder. To view a copy of this licence, visit http://creativecommons.org/licenses/by/4.0/.

\section{References}

Ajayi T, Gomes JS, Bera A. A review of $\mathrm{CO}_{2}$ storage in geological formations emphasizing modeling, monitoring and capacity estimation approaches. Pet Sci. 2019;16(5):1028-63. https://doi. org/10.1007/s12182-019-0340-8.

Cerit M. Corrosion pit-induced stress concentration in spherical pressure vessel. Thin-Walled Struct. 2019;136:106-12. https://doi. org/10.1016/j.tws.2018.12.014.

Chen M, Wang H, Liu Y, Ma L, Wu D, Wang S. Corrosion behavior study of oil casing steel on alternate injection air and foam liquid in air-foam flooding for enhance oil recovery. J Pet Sci Eng. 2018;165(8):970-7. https://doi.org/10.1016/j.petrol.2017.09.081.

Duguid A, Zaluski W, El-Kaseeh G, Lee SY, Piercy M. Well integrity risk assessment to inform containment risk monitoring for carbon capture, utilization, and storage, applied to the Weyburn-Midale Field, Canada. Int J Greenh Gas Control. 2019;86:226-38. https ://doi.org/10.1016/j.ijggc.2016.10.018.

Elgaddafi R, Ahmed R, Hassani S, Shah S, Osisanya SO. Corrosion of $\mathrm{C} 110$ carbon steel in high-pressure aqueous environment with mixed hydrocarbon and $\mathrm{CO}_{2}$ gas. J Pet Sci Eng. 2016;146:777-87.

Fu AQ, Feng YR, Cai R, Yuan JT, Yin CX, Yang DM, et al. Downhole corrosion behavior of NiW coated carbon steel in spent acid \& formation water and its application in full-scale tubing. Eng Fail Anal. 2016;66:566-76.

Gao Y, Liu L, Liu H, Zheng F, Wu L, Zhou J, et al. Application of an analytic hierarchy process to hydrocarbon accumulation coefficient estimation. Pet Sci. 2010;7(3):337-46.

Guo YB, Liu C, Wang DG, Liu SH. Effects of alternating current interference on corrosion of X60 pipeline steel. Pet Sci. 2015;12(2):316-24. https://doi.org/10.1007/s12182-015-0022-0.

Guo Y, Meng X, Meng T, Wang D, Liu S. A novel method of risk assessment based on cloud inference for natural gas pipelines. J
Nat Gas Sci Eng. 2016a;30:421-9. https://doi.org/10.1016/j.jngse .2016.02.051.

Guo Y, Meng X, Wang D, Meng T, Liu S, He R. Comprehensive risk evaluation of long-distance oil and gas transportation pipelines using a fuzzy Petri net model. J Nat Gas Sci Eng. 2016b;33:18-29. https://doi.org/10.1016/j.jngse.2016.04.052.

Guo T, Tang S, Sun J, Gong F, Liu X, Qu Z, et al. A coupled thermalhydraulic-mechanical modeling and evaluation of geothermal extraction in the enhanced geothermal system based on analytic hierarchy process and fuzzy comprehensive evaluation. Appl Energy. 2020;258:113981. https://doi.org/10.1016/j.apene rgy.2019.113981.

Han C, Zhang J, Liang Z. Thermal failure of rubber bushing of a positive displacement motor: a study based on thermo-mechanical coupling. Appl Therm Eng. 2014;67(1-2):489-93. https://doi. org/10.1016/j.applthermaleng.2014.03.072.

Hu J, Chen J, Chen Z, Cao J, Wang Q, Zhao L, et al. Risk assessment of seismic hazards in hydraulic fracturing areas based on fuzzy comprehensive evaluation and AHP method (FAHP): a case analysis of Shangluo area in Yibin City, Sichuan Province, China. J Pet Sci Eng. 2018;170:797-812. https://doi.org/10.1016/j.petro 1.2018.06.066

Hua Y, Xu S, Wang Y, Taleb W, Sun J, Zhang L, et al. The formation of $\mathrm{FeCO}_{3}$ and $\mathrm{Fe}_{3} \mathrm{O}_{4}$ on carbon steel and their protective capabilities against $\mathrm{CO}_{2}$ corrosion at elevated temperature and pressure. Corros Sci. 2019;157:392-405. https://doi.org/10.1016/j.corsc i.2019.06.016.

Kalra S, Tian W, Wu X. A numerical simulation study of $\mathrm{CO}_{2}$ injection for enhancing hydrocarbon recovery and sequestration in liquidrich shales. Pet Sci. 2018;15(1):103-15.

Khather M, Saeedi A, Myers MB, Verrall M. An experimental study for carbonate reservoirs on the impact of $\mathrm{CO}_{2}$-EOR on petrophysics and oil recovery. Fuel. 2019;235:1019-38. https://doi. org/10.1016/j.fuel.2018.08.094.

Laumb JD, Glazewski KA, Hamling JA, Azenkeng A, Watson TL. Wellbore corrosion and failure assessment for $\mathrm{CO}_{2} \mathrm{EOR}$ and storage: two case studies in the Weyburn field. Int J Greenh Gas Control. 2016;54:479-89. https://doi.org/10.1016/j.ijggc.2016.08.031.

Li W, Pots BFM, Zhong X, Nesic S. Inhibition of $\mathrm{CO}_{2}$ corrosion of mild steel: study of mechanical effects of highly turbulent disturbed flow. Corros Sci. 2017;126:208-26. https://doi.org/10.1016/j.corsc i.2017.07.003.

Li X, Pearson P, Yang Q, Puxty G, Feron P, Xiao D. A study of designer amine 4-amino-1-propyl-piperidine against the corrosion of carbon steel for application in $\mathrm{CO}_{2}$ capture. Int J Greenh Gas Control. 2020;94:102929. https://doi.org/10.1016/j.ijggc.2019.102929.

Lin T, Zhang Q, Lian Z, Chang X, Zhu K, Liu Y. Evaluation of casing integrity defects considering wear and corrosion: application to casing design. J Nat Gas Sci Eng. 2016;29:440-52. https://doi. org/10.1016/j.jngse.2016.01.029.

Liu GL. A novel limiting strain energy strength theory. Trans Nonferr Met Soc China. 2009;19(6):1651-62. https://doi.org/10.1016/ S1003-6326(09)60084-4.

Marques F, Correia JAFO, de Jesus AMP, Cunha Á, Caetano E, Fernandes AA. Fatigue analysis of a railway bridge based on fracture mechanics and local modelling of riveted connections. Eng Fail Anal. 2018;94:121-44. https://doi.org/10.1016/j.engfailana 1.2018.07.016.

Mohammed AI, Oyeneyin B, Atchison B, Njuguna J. Casing structural integrity and failure modes in a range of well types: a review. $\mathrm{J}$ Nat Gas Sci Eng. 2019;68:102898. https://doi.org/10.1016/j.jngse .2019.05.011

NACE RP0775-2005. Preparation and installation of corrosion coupons and interpretation of test data in oilfield operations. Houston: NACE International Publication; 2005. 
Okoro EE, Kurah AM, Sanni SE, Dosunmu A, Ekeinde EB. Flow line corrosion failure as a function of operating temperature and $\mathrm{CO}_{2}$ partial pressure using real time field data. Eng Fail Anal. 2019;102:160-9. https://doi.org/10.1016/j.engfailana 1.2019.04.037.

Rizzo R, Baier S, Rogowska M, Ambat R. An electrochemical and $\mathrm{X}$-ray computed tomography investigation of the effect of temperature on $\mathrm{CO}_{2}$ corrosion of $1 \mathrm{Cr}$ carbon steel. Corros Sci. 2020;166:108471. https://doi.org/10.1016/j.corsci.2020.108471.

Saaty TL. Ranking by eigenvector versus other methods in the analytic hierarchy process. Appl Math Lett. 1998;11(4):121-5.

Sim S, Cole IS, Bocher F, Corrigan P, Gamage RP, Ukwattage N, et al. Investigating the effect of salt and acid impurities in supercritical $\mathrm{CO}_{2}$ as relevant to the corrosion of carbon capture and storage pipelines. Int J Greenh Gas Control. 2013;17:534-41. https://doi. org/10.1016/j.ijggc.2013.06.013.

Song QQ, Jiang QZ, Song ZZ. Optimization of $\mathrm{CO}_{2}$ separation technologies for Chinese refineries based on a fuzzy comprehensive evaluation model. Pet Sci. 2015;12(1):197-206.

Sui P, Sun J, Hua Y, Liu H, Zhou M, Zhang Y, et al. Effect of temperature and pressure on corrosion behavior of X65 carbon steel in water-saturated $\mathrm{CO}_{2}$ transport environments mixed with $\mathrm{H}_{2} \mathrm{~S}$. Int J Greenh Gas Control. 2018;73:60-9. https://doi.org/10.1016/j. ijggc.2018.04.003.

Sun JB, Zhang GA, Liu W, Lu MX. The formation mechanism of corrosion scale and electrochemical characteristic of low alloy steel in carbon dioxide-saturated solution. Corros Sci. 2012;57:131-8.

Sun C, Sun J, Wang Y, Sui P, Lin X, Liu H, et al. Effect of impurity interaction on the corrosion film characteristics and corrosion morphology evolution of X65 steel in water-saturated supercritical $\mathrm{CO}_{2}$ system. Int J Greenh Gas Control. 2017;65:117-27. https ://doi.org/10.1016/j.ijggc.2017.09.002.

Sun C, Sun J, Luo JL. Unlocking the impurity-induced pipeline corrosion based on phase behavior of impure $\mathrm{CO}_{2}$ streams. Corros Sci. 2020;165:108367. https://doi.org/10.1016/j.corsci.2019.108367.

Wang X, Duan Q. Improved AHP-TOPSIS model for the comprehensive risk evaluation of oil and gas pipelines. Pet Sci. 2019;16(6):1479-92. https://doi.org/10.1007/s12182-019-00365-5.
Wang Y, Yang W, Li M, Liu X. Risk assessment of floor water inrush in coal mines based on secondary fuzzy comprehensive evaluation. Int J Rock Mech Min Sci. 2012;52:50-5. https://doi.org/10.1016/j. ijrmms.2012.03.006.

Wang Q, Zhang L, Hu J. Real-time risk assessment of casing-failure incidents in a whole fracturing process. Process Saf Environ Prot Inst Chem Eng. 2018;120:206-14. https://doi.org/10.1016/j.psep.2018.06.039.

Wen Z, Sheng Y, Jin H, Li S, Li G, Niu Y. Thermal elasto-plastic computation model for a buried oil pipeline in frozen ground. Cold Reg Sci Technol. 2010;64(3):248-55. https://doi.org/10.1016/j. coldregions.2010.01.009.

William Carey J, Svec R, Grigg R, Zhang J, Crow W. Experimental investigation of wellbore integrity and $\mathrm{CO}_{2}$-brine flow along the casing-cement microannulus. Int $\mathrm{J}$ Greenh Gas Control. 2010;4(2):272-82. https://doi.org/10.1016/j.ijggc.2009.09.018.

Yan Y, Shao B, Zhou X, Song S, Zhou X, Yan X. A study on the influence of double ellipsoidal pitting corrosion on the collapsing strength of the casing. Eng Fail Anal. 2019;100:11-24. https://doi. org/10.1016/j.engfailanal.2019.02.020.

Zeng D, He Q, Yu Z, Jia W, Zhang S, Liu Q. Risk assessment of sustained casing pressure in gas wells based on the fuzzy comprehensive evaluation method. J Nat Gas Sci Eng. 2017;46:756-63. https://doi.org/10.1016/j.jngse.2017.08.019.

Zhang H, Gao D, Hao Z. Risk analysis of extended reach wells in the Liuhua Oilfield, South China Sea, based on comprehensive fuzzy evaluation method. Pet Sci. 2009;6(2):172-5.

Zhang GA, Zeng L, Huang HL, Guo XP. A study of flow accelerated corrosion at elbow of carbon steel pipeline by array electrode and computational fluid dynamics simulation. Corros Sci. 2013;77:334-41. https://doi.org/10.1016/j.corsci.2013.08.022.

Zhong X, Shang T, Zhang C, Hu J, Zhang Z, Zhang Q, et al. In situ study of flow accelerated corrosion and its mitigation at different locations of a gradual contraction of N80 steel. J Alloys Compd. 2020;824:153947. https://doi.org/10.1016/j.jallcom.2020.153947.

Zhu X, Liu B. The reliability-based evaluation of casing collapsing strength and its application in marine gas reservoirs. Eng Fail Anal. 2018;85:1-13. https://doi.org/10.1016/j.engfailana 1.2017.12.005. 